\title{
Retrospective evaluation of deep transcranial magnetic stimulation as add-on treatment for Parkinson's disease
}

Francisco Torres ${ }^{1}$, Esteban Villalon ${ }^{1}$, Patricio Poblete ${ }^{1}$, Rodrigo Moraga-Amaro ${ }^{2}$, Sergio Linsambarth ${ }^{2}$, Raúl Riquelme ${ }^{1}$, Abraham Zangen ${ }^{3}$ and Jimmy Stehberg ${ }^{2 *}$

\section{OPEN ACCESS}

Edited by:

Oscar Arias-Carrión,

Hospital General Dr. Manuel Gea

González, Mexico

Reviewed by:

Manuel Menéndez-González,

Hospital Álvarez-Buylla, Spain

Pedro Ribeiro,

Federal University of Rio de Janeiro,

Brazil

${ }^{*}$ Correspondence:

Jimmy Stehberg,

Laboratorio de Neurobiología, Centro

de Investigaciones Biomédicas,

Universidad Andres Bello, República

217, Santiago 8370146, Chile jstehberg@unab.cl

Specialty section:

This article was submitted to Movement Disorders, a section of the

journal Frontiers in Neurology

Received: 06 May 2015 Accepted: 16 September 2015

Published: 26 October 2015

Citation:

Torres $F$, Villalon E, Poblete $P$, Moraga-Amaro R, Linsambarth $S$,

Riquelme $R$, Zangen $A$ and Stehberg J (2015) Retrospective

evaluation of deep transcranial magnetic stimulation as add-on treatment for Parkinson's disease.

Front. Neurol. 6:210.

doi: 10.3389/fneur.2015.00210
${ }^{1}$ Neuromagnetics, Santiago, Chile, ${ }^{2}$ Laboratorio de Neurobiología, Centro de Investigaciones Biomédicas, Universidad Andres Bello, Santiago, Chile, ${ }^{3}$ Neuroscience Laboratory, Ben-Gurion University of the Negev, Beersheva, Israel

Objective: To evaluate the safety and assess the different symptom improvements found after a combined low-frequency primary motor cortex and high-frequency prefrontal cortex (PFC) stimulation using the deep TMS (dTMS) H-coil, as an add-on treatment for Parkinson's disease (PD).

Methods: Forty-five PD patients underwent 14 dTMS sessions; each consisting of $1 \mathrm{~Hz}$ stimulation of the primary motor cortex for $15 \mathrm{~min}$, followed by $10 \mathrm{~Hz}$ stimulation of the PFC for 15 min. Clinical assessments were performed, BEFORE, at the MIDDLE, and END of therapy as well as at FOLLOW-UP after 30 days, using Movement Disorder Society-Unified Parkinson's Disease Rating Scale, TINETTI, UP\&GO, SCOPA, HDRS 21 , Beck Depression Inventory, and self-applied daily motor assessment scales.

Results: Treatment was well-tolerated, without serious adverse effects. dTMS-induced significant PD symptom improvements at END and at FOLLOW-UP, in all subscales of the UPDRS, gait speed, depressive symptoms, balance, autonomic symptoms, and a $73 \%$ increase in daily $\mathrm{ON}$ time.

Conclusion: In the cohort of PD patients treated, dTMS was well-tolerated with only minor adverse effects. The dTMS-induced significant improvements in motor, postural, and motivational symptoms of PD patients and may potentiate concurrent levodopa treatment.

Significance: The present study demonstrates that dTMS may have a much wider spectrum of beneficial effects than previously reported for TMS, including enhancement of levodopa effects, suggesting that future clinical trials with dTMS should include a broader range of symptom measurements.

Keywords: Parkinson's disease, repetitive transcranial magnetic stimulation, H-coil, motor cortex, prefrontal cortex, high and low frequency, deep TMS 


\section{Introduction}

Parkinson's disease (PD) is a chronic, progressive disorder for which there is no satisfactory long-term treatment. The gold standard pharmacological treatment for PD is orally administered levodopa. Levodopa, while highly effective at controlling motor symptoms for a limited time, shows progressive decrease in efficacy as the disease progresses. This demands a constant increase in dosage to manage symptoms, resulting in a mirrored increase in treatment-related adverse effects. This has led to the development of several drugs, including dopaminergic agonists, which are combined with levodopa to improve PD symptoms and control its adverse effects. As the disease progresses, PD symptoms and adverse effects re-emerge, highlighting the need for the development of novel therapies that can improve PD symptoms and related comorbidities.

Focal neuromodulation with repetitive transcranial magnetic stimulation (rTMS) has raised increased interest over the past few years as a promising coadjuvant treatment for many neurological and psychiatric disorders, including PD, as it induces changes in cortical excitability non-invasively $(1,2)$ that persist after stimulation, with cumulative effects over time (3).

Several studies have found that high-frequency stimulation of the motor cortex with rTMS $(5-10 \mathrm{~Hz})$ improves motor symptoms in PD patients $(1,4-9)$ and produces enduring cortical excitation (2, 10-12).

However, several studies have reported that PD patients suffer from impaired intra-cortical inhibition (13-17), suggesting that low-frequency stimulation of the motor cortex may be more beneficial in PD. Indeed, rTMS of the primary motor cortex (M1) with low frequencies $(0.1-1 \mathrm{~Hz})$ has been shown to produce significant improvement in motor symptoms of PD patients $(6,18)$ and long-lasting increases in intra-cortical inhibition (19-21). A recent meta-analysis that included eight randomized placebocontrolled trials that used low frequency rTMS to M1 showed significant improvements in $\mathrm{PD}$ motor symptoms compared to placebo (22).

High-frequency rTMS of the prefrontal cortex (PFC) has also been shown to improve motor symptoms (23). This improvement is potentially explained by an increase in striatal dopamine release (24).

A new coil for TMS, known as deep TMS H-coil (dTMS) designed to stimulate deep cortical areas with lower intensities than conventional coils (25) has been reported to induce significant improvements in motor symptoms (26) in PD patients. The objective of the present study is to retrospectively evaluate the effectiveness and safety of dTMS as an add-on treatment for $\mathrm{PD}$, using a combination of low frequency $(1 \mathrm{~Hz})$ stimulation of M1 and high-frequency stimulation of PFC, and to analyze the effects of treatment using a wide range of motor and non-motor evaluations.

\section{Materials and Methods}

\section{Patients}

The present study was performed according to the Declaration of Helsinki and following a protocol approved by the Ethical
Committee of the Universidad Andrés Bello (0072015). Fortyfive PD patients ( 26 men, 19 women) were included in the study and attended Neuromagnetics for dTMS treatment between October 2012 and September 2014. Each participant signed an informed consent. Patients were non-demented adults suffering from idiopathic PD, according to previously established clinical criteria (27).

The inclusion criteria consisted of a PD diagnosis, pharmacological treatment with levodopa or dopaminergic agonists, and the ability to provide oral or written informed consent. The exclusion criteria included neurological or psychiatric disorders other than PD and depression, recent head trauma, personal or family history of seizures, presence of metal implants, pacemakers or DBS, and uncompensated or non-medicated chronic medical conditions (such as hypertension or diabetes).

\section{Deep Transcranial Magnetic Stimulation}

A dTMS H2 par coil (Brainsway Inc., Israel), designed to bilaterally stimulate the complete cortical thickness (25), was used with a Rapid2 MagStim stimulator (MagStim Company, Ltd., Carmarthenshire, Wales, UK). The total duration of the stimulation protocol was 3 weeks. Patients underwent 5 sessions of dTMS per week for a total of 12-16 sessions (14 sessions on average), and were evaluated at 30 days post-treatment. Each session consisted of $16 \mathrm{~min}$ of $1 \mathrm{~Hz}$ dTMS to M1 and $16 \mathrm{~min}$ of $10 \mathrm{~Hz}$ stimulation to the lateral PFC. For stimulation, the coil was first located over the M1 and tilted in the coronal/sagittal planes to a position that induced hand movements when stimulated. Resting motor threshold (RMT) was determined as the lowest stimulation intensity capable of inducing thumb movement as measured by evoked potentials using an EMG of the abductor pollicis brevis muscle. Stimulation of M1 was bilateral with stimulus intensity set at $110 \%$ of RMT ( 900 stimuli, 90 trains of 10 pulses at $1 \mathrm{~Hz}$, $1 \mathrm{~s}$ inter-train interval). For PFC stimulation, the coil was moved $6 \mathrm{~cm}$ anterior symmetrically from the RMT location and stimulation intensity was set at 100\% RMT (1000 stimuli, 50 trains of 20 pulses at $10 \mathrm{~Hz}, 18 \mathrm{~s}$ inter-train interval). $1 \mathrm{~Hz}$ stimulation of M1 always preceded $10 \mathrm{~Hz}$ stimulation of PFC.

\section{Clinical Measures}

Clinical assessments were performed during patients' $\mathrm{ON}$ state, at the same time of day, at baseline (BEFORE), after 6 daily sessions (MID), after completion of treatment (END), and 30 days after the end of treatment (FOLLOW-UP).

All patients were evaluated with (1) Hoehn and Yahr (H\&Y) stages evaluation for PD severity (28) and with (2) the Movement Disorder Society-Unified Parkinson's Disease Rating Scale (MDSUPDRS), including Part I [non-motor activities of daily living (ADL)], Part II (motor ADL), Part III (motor examination), and Part IV (motor complications) (29). (3) The SCOPA-AUT (30, 31 ) to measure autonomic symptoms in PD, including subscales for cardiovascular, urinary, sexual, thermoregulation, and gastrointestinal dysfunction, (4) the UP\&GO to measure gait speed (32), (5) the Tinetti for risk of fall (33), (6) the Hamilton Rating Scale for Depression $\left(\mathrm{HDRS}_{21}\right)$ (34), (7) the Beck Depression Inventory (BDI) (35) to assess depressive symptoms, and (8) a self-assessment of ON\&OFF daily periods. 


\section{Safety}

Patients were asked to report every potential adverse effect, including side effects previously associated to TMS or dTMS, such as discomfort, headache, toothache, facial ache, seizures, pain, cognitive effects, nausea, motor effects/weakness, sleep/ tiredness, and auditory effects $(36,37)$.

\section{Statistical Analysis}

Statistical analysis was performed using GraphPad Prism v5. All patient data were analyzed using a one-way repeated measures ANOVA to assess differences between three time-points of testing (BEFORE, MID, and END) using TIME as a factor at three levels for each scale, except for SCOPA. SCOPA was only measured at BEFORE and END and was analyzed using a paired $t$-test.

Data from the 22 patients that attended the 30-day FOLLOW-UP session were used to analyze the post-treatment effects of dTMS stimulation with the MDS-UPDRS scale. For other scales, data are available from only 16 patients that attended the FOLLOW-UP session. A one-way repeated measures ANOVA was used to assess the difference between the three time points (BEFORE, END, and FOLLOW-UP). The ON\&OFF evaluation was not measured at FOLLOW-UP.

To test for differences in treatment effects between patients who were depressive and those who were not depressive BEFORE treatment, patients were divided into two groups; those that had seven or less points and those that had more than seven points in the HDRS 2 . A one-way repeated measures ANOVA was used to assess the difference between the three time points (BEFORE, END, and FOLLOW-UP) for each curve. Then, a two-way ANOVA with a Bonferroni post hoc test was used to assess differences between the two curves at each time point. Finally, to assess differences in the improvements in motor UPDRS for between groups, the difference between BEFORE and END for each group was compared between the groups using a paired $t$-test.

To test for differences between gender, physical activity and UP\&GO improvement, ANOVA was performed with TIME (4 levels) and GENDER or SPORT or UP\&GO time (2 levels). ANOVA was also performed using UP\&GO initial severity (time) (1 level) and \% of improvement in the UP\&GO (difference in time to perform the task between BEFORE and END). Post hoc comparisons were performed using the Bonferroni test. Multivariate analysis and possible correlations between initial symptoms, motor improvements, and clinical demographics [age, disease duration, H\&Y scale, levodopa equivalent daily dose (LEDD) and baseline motor scores] were analyzed using Spearman's test. A $p$-value $<0.05$ was considered statistically significant.

\section{Results}

Forty-five patients with PD were evaluated and treated with at least 12 sessions of dTMS, with an average of $13.6 \pm 0.5$ sessions. The patients were on average $62.5 \pm 1.6$ years old, had an H\&Y score of $2.3 \pm 0.2$ and $9.8 \pm 0.9$ years since diagnosed. To see details of patient demographics see Table 1. Although 32 patients returned for assessment 30 days after treatment (FOLLOW-UP) and had their MDS-UPDRS evaluation, only 16 of them completed the evaluation for the other scales. Most patients who failed to attend the FOLLOW-UP session reported by phone not to have attended because they felt well and preferred to postpone treatment sessions while being asymptomatic. Others reported being busy and not having sufficient time to attend. From the 32 patients who attended FOLLOW-UP, 16 were only evaluated using the MDS-UPDRS reportedly because they did not have sufficient time that day to complete the other evaluations besides the MDS-UPDRS. Average LEDD was $470.72 \mathrm{mg}$ at BEFORE and did not change significantly throughout the study, being $478.62 \mathrm{mg}$ at END. The medications used were Levodopa (565.2 $\pm 9.9 \mathrm{mg}$; $80 \%$ patients); pramipexole $(2.2 \pm 0.1 \mathrm{mg} ; 68 \%$ of patients); hydrochlorothiazide (50 $\pm 0 \mathrm{mg} ; 3 \%$ ); citalopram (20 $\pm 0 \mathrm{mg}$; $8 \%$ ); Resagiline ( $1 \pm 0 \mathrm{mg} ; 3 \%)$. Three patients were not taking medication during treatment.

For a detailed summary of results from all 45 patients, see Table 2 and for those patients that attended the FOLLOW-UP session see Table 3.

\section{Safety}

Treatment was well-tolerated with 100\% adherence (no drop-outs) until the end of treatment. Patients reported only mild and short lasting adverse effects; eight patients experienced sleepiness, six had headaches during the first sessions and two reported nausea. No serious adverse effects were reported.

\section{Non-Motor Activities of Daily Living (Non-Motor ADL, MDS-UPDRS Part I)}

Data showed a strong, significant correlation between time $(F=50.74 ; p<0.0001)$ and non-motor ADL (Figure 1A), with a significant point reduction between BEFORE and MID

TABLE 1 | Demographics and clinical characteristics of PD patients.

\begin{tabular}{|c|c|c|c|c|c|c|c|c|c|}
\hline & \multicolumn{3}{|c|}{ All patients } & \multicolumn{3}{|c|}{ Physical activity } & \multicolumn{3}{|c|}{ No physical activity } \\
\hline & All & Female & Male & All & Female & Male & All & Female & Male \\
\hline Number of patients & 45 & 19 & 26 & 26 & 12 & 14 & 19 & 7 & 12 \\
\hline Average age (years) & $62.5 \pm 1.6$ & $63.7 \pm 2.4$ & $61.5 \pm 2.1$ & $61.7 \pm 2.0$ & $64.4 \pm 3.0$ & $59.3 \pm 2.6$ & $63.6 \pm 2.6$ & $62.6 \pm 4.3$ & $64.2 \pm 3.4$ \\
\hline Average years disease & $9.8 \pm 0.9$ & $10.4 \pm 1.4$ & $9.4 \pm 1.1$ & $10.3 \pm 1.2$ & $10.9 \pm 2.0$ & $9.9 \pm 1.6$ & $9.1 \pm 1.3$ & $9.4 \pm 1.9$ & $8.0 \pm 2.4$ \\
\hline Average severity & $2.6 \pm 0.1$ & $2.7 \pm 0.2$ & $2.6 \pm 0.2$ & $2.4 \pm 0.2$ & $2.6 \pm 0.2$ & $2.5 \pm 0.2$ & $2.7 \pm 0.2$ & $2.9 \pm 0.5$ & $2.3 \pm 0.4$ \\
\hline Sessions & $13.6 \pm 0.5$ & $14.2 \pm 0.9$ & $13.1 \pm 0.4$ & $13.8 \pm 0.8$ & $14.3 \pm 1.5$ & $13.3 \pm 0.7$ & $13.4 \pm 0.4$ & $14.1 \pm 0.6$ & $12.5 \pm 0.5$ \\
\hline
\end{tabular}

The number of patients, their gender, age, years of disease, disease severity (according to Hoehn and Yahr), and number of stimulation sessions are shown for all patients and subdivided according to their physical activity (all data shown as average \pm SE). 
TABLE 2 | Summary of results.

\begin{tabular}{|c|c|c|c|c|c|c|}
\hline & $N$ & Start & Middle & End & $p$-Value & $\Delta$ \\
\hline \multicolumn{7}{|l|}{ MDS-UPDRS } \\
\hline Non-motor aspects of activities of daily living & 45 & $11.3 \pm 0.9$ & $8.5 \pm 0.8$ & $7.1 \pm 0.8$ & $<0.0001$ & $4.1 \pm 0.5$ \\
\hline Motor aspects of activities of daily living & 45 & $16.4 \pm 1.1$ & $13.8 \pm 1.1$ & $12.2 \pm 1.1$ & $<0.0001$ & $4.3 \pm 0.5$ \\
\hline Motor examination & 45 & $37.0 \pm 2.3$ & $34.0 \pm 2.5$ & $28.5 \pm 2.3$ & $<0.0001$ & $8.7 \pm 1.0$ \\
\hline Motor complications & 45 & $5.3 \pm 0.7$ & $4.3 \pm 0.5$ & $4.2 \pm 0.5$ & $<0.0001$ & $1.4 \pm 0.4$ \\
\hline Total & 45 & $70.0 \pm 3.8$ & $60.6 \pm 4.0$ & $50.8 \pm 4.0$ & $<0.0001$ & $20.5 \pm 2.4$ \\
\hline \multicolumn{7}{|l|}{ SCOPA-AUT } \\
\hline Gastrointestinal & 45 & $3.2 \pm 0.4$ & - & $2.0 \pm 0.3$ & $<0.001$ & $1.2 \pm 0.3$ \\
\hline Urinary & 45 & $3.2 \pm 0.5$ & - & $1.7 \pm 0.3$ & $<0.0001$ & $1.5 \pm 0.3$ \\
\hline Cardiovascular & 45 & $3.6 \pm 0.5$ & - & $1.7 \pm 0.3$ & $<0.0001$ & $2.0 \pm 0.4$ \\
\hline Thermoregulation & 45 & $2.1 \pm 0.4$ & - & $1.6 \pm 0.4$ & $>0.05$ & $0.7 \pm 0.3$ \\
\hline Sexual & 45 & $1.3 \pm 0.5$ & - & $1.0 \pm 0.4$ & $>0.05$ & $0.1 \pm 0.1$ \\
\hline Total & 45 & $12.7 \pm 1.2$ & - & $7.5 \pm 1.0$ & $<0.0001$ & $5.1 \pm 0.7$ \\
\hline \multicolumn{7}{|l|}{ On-Off } \\
\hline ON time (h/day) & 14 & $4.4 \pm 1.2$ & $7.2 \pm 1.2$ & $7.6 \pm 1.2$ & $<0.05$ & $3.2 \pm 1.5$ \\
\hline OFF time (h/day) & 14 & $10.4 \pm 1.3$ & $7.7 \pm 1.2$ & $7.2 \pm 1.3$ & $<0.05$ & $3.2 \pm 1.7$ \\
\hline$\% O N$ & 14 & $30.4 \pm 8.5$ & $48.7 \pm 7.5$ & $51.61 \pm 8.2$ & $<0.05$ & $21.0 \pm 11.1$ \\
\hline$\% O F F$ & 14 & $69.3 \pm 8.6$ & $51.3 \pm 7.6$ & $48.3 \pm 8.2$ & $<0.05$ & $20.8 \pm 11.1$ \\
\hline UP\&GO & 45 & $17.0 \pm 3.7$ & $11.2 \pm 0.8$ & $9.7 \pm 0.4$ & $<0.05$ & $7.7 \pm 3.9$ \\
\hline \multicolumn{7}{|l|}{ Tinettl } \\
\hline Gait & 45 & $7.6 \pm 0.3$ & $9.5 \pm 0.2$ & $10.0 \pm 0.2$ & $<0.0001$ & $2.3 \pm 0.3$ \\
\hline Static balance & 45 & $12.0 \pm 0.3$ & $14.1 \pm 0.3$ & $14.5 \pm 0.3$ & $<0.0001$ & $2.6 \pm 0.4$ \\
\hline $\mathrm{BDI}$ & 45 & $10.7 \pm 1.2$ & $6.8 \pm 0.9$ & $5.4 \pm 0.9$ & $<0.0001$ & $5.4 \pm 1.0$ \\
\hline HDRS-21 & 45 & $11.3 \pm 1.1$ & $6.5 \pm 0.9$ & $5.5 \pm 0.9$ & $<0.0001$ & $5.8 \pm 1.0$ \\
\hline \multicolumn{7}{|l|}{ RS } \\
\hline Depressive & 25 & $19.1 \pm 1.6$ & $16.2 \pm 1.7$ & $14.8 \pm 1.7$ & $<0.0001$ & $4.0 \pm 1.1$ \\
\hline Non-depressive & 20 & $13.1 \pm 1.1$ & $10.8 \pm 1.0$ & $9.0 \pm 0.8$ & $<0.0001$ & $3.1 \pm 0.3$ \\
\hline
\end{tabular}

Results from the different scales are shown for each time point (Before, Middle and End) for the 45 patients. Significance is shown as ${ }^{*} p<0.05 ;{ }^{* *} p<0.01 ;{ }^{* * *} p<0.001 ; p$-value and the difference between Before and End time points are also shown. All results appear as average \pm SEM.

TABLE 3 | Summary of results from patients with 30 -day follow-up.

\begin{tabular}{|c|c|c|c|c|c|c|}
\hline & $N$ & Start & End & Follow-up & $p$-Value & $\Delta$ \\
\hline \multicolumn{7}{|l|}{ MDS-UPDRS } \\
\hline Non-motor aspects of activities of daily living & 32 & $11.6 \pm 0.9$ & $7.3 \pm 0.8$ & $2.9 \pm 0.9$ & $<0.0001$ & $8.7 \pm 0.8$ \\
\hline Motor aspects of activities of daily living & 32 & $15.6 \pm 1.2$ & $10.9 \pm 0.9$ & $10.8 \pm 0.9$ & $<0.0001$ & $4.7 \pm 0.6$ \\
\hline Motor examination & 32 & $33.1 \pm 2.6$ & $24.8 \pm 2.2$ & $21.0 \pm 2.2$ & $<0.0001$ & $12.1 \pm 0.9$ \\
\hline Motor complications & 32 & $5.8 \pm 0.7$ & $4.1 \pm 0.5$ & $4.5 \pm 0.6$ & $<0.01$ & $1.3 \pm 0.7$ \\
\hline Total & 32 & $63.0 \pm 4.3$ & $47.1 \pm 3.6$ & $39.2 \pm 3.6$ & $<0.0001$ & $24.3 \pm 1.9$ \\
\hline \multicolumn{7}{|l|}{ SCOPA-AUT } \\
\hline Gastrointestinal & 16 & $3.3 \pm 0.7$ & $2.1 \pm 0.6$ & $2.6 \pm 0.7$ & $<0.05$ & $0.6 \pm 0.5$ \\
\hline Urinary & 16 & $2.8 \pm 0.7$ & $1.4 \pm 0.6$ & $1.6 \pm 0.7$ & $<0.05$ & $1.1 \pm 0.5$ \\
\hline Cardiovascular & 16 & $3.6 \pm 0.9$ & $1.4 \pm 0.5$ & $1.3 \pm 0.3$ & $<0.01$ & $2.2 \pm 0.7$ \\
\hline Thermoregulation & 16 & $1.6 \pm 0.5$ & $1.2 \pm 0.4$ & $1.0 \pm 0.4$ & $>0.05$ & $0.6 \pm 0.5$ \\
\hline Sexual & 9 & $1.3 \pm 0.7$ & $0.9 \pm 0.5$ & $0.9 \pm 0.4$ & $>0.05$ & $0.4 \pm 0.4$ \\
\hline Total & 16 & $11.9 \pm 1.7$ & $6.6 \pm 1.7$ & $7.1 \pm 1.5$ & $<0.0001$ & $4.9 \pm 1.3$ \\
\hline \multicolumn{7}{|l|}{ TINETTI } \\
\hline Gait & 16 & $7.3 \pm 0.5$ & $10.1 \pm 0.3$ & $9.9 \pm 0.4$ & $<0.0001$ & $2.4 \pm 0.6$ \\
\hline Static balance & 16 & $12.0 \pm 0.7$ & $14.7 \pm 0.4$ & $14.6 \pm 0.4$ & $<0.0001$ & $3.2 \pm 0.7$ \\
\hline $\mathrm{BDI}$ & 16 & $9.1 \pm 1.6$ & $4.9 \pm 1.5$ & $6.3 \pm 1.5$ & $<0.01$ & $3.9 \pm 0.8$ \\
\hline HDRS-21 & 16 & $9.3 \pm 1.4$ & $3.6 \pm 1.5$ & $5.6 \pm 0.7$ & $<0.001$ & $4.3 \pm 0.6$ \\
\hline
\end{tabular}

Results from the different scales are shown for each time point (Before, End and FOLLOW-UP) for the patients who attended the FOLLOW-UP session 30 days after treatment (N is number of patients with data and delta corresponds to the change in scale in points). Significance is shown as ${ }^{*} p<0.05 ;{ }^{* *} p<0.01$; ${ }^{* * *} p<0.001 ; p$-value and the difference between BEFORE and END time points are also shown. All results appear as average \pm SEM. 
$(11.3 \pm 0.9-8.5 \pm 0.8$ points; $p<0.001)$, BEFORE and END $(11.3 \pm 0.9-7.1 \pm 0.8$ points; $p<0.001)$, and MID and END $(8.5 \pm 0.8-7.1 \pm 0.8$ points; $p<0.001)$. In the case of the patients that attended the 30-day, post-treatment FOLLOW-UP (Figure 1E), they showed a significant decrease $(F=8.510 ; p<0.0001)$ from BEFORE to END $(11.6 \pm 1.0-7.3 \pm 0.8$ points; $p<0.001)$, between BEFORE and FOLLOW-UP (11.6 $\pm 1.0-2.9 \pm 0.9$ points; $p<0.001)$, and from END to FOLLOW-UP $(7.3 \pm 0.8-2.9 \pm 0.9$ points; $p<0.001$ ), suggesting further improvements 30 days post-treatment, beyond the improvements attained by the END of treatment.

\section{Motor Activities of Daily Living (Motor ADL, MDS-UPDRS Part II)}

A significant relationship between time $(F=42.07 ; p<0.0001)$ and motor ADL was found (Figure 1B). Significant symptom improvements were found between BEFORE and MID (from $16.4 \pm 1.2$ to $13.8 \pm 1.1$ points; $p<0.001$ ), between BEFORE and END (reduction from $16.4 \pm 1.2$ to $12.2 \pm 1.1$ points; $p<0.001$ ), and between MID and END (reduction from $13.8 \pm 1.1$ to $12.2 \pm 1.1$ points; $p<0.001$ ). For the group of patients that attended the FOLLOW-UP session (Figure 1F), the statistically significant improvement between BEFORE and END $(F=18.58 ; p<0.0001)$ (reduction from $15.6 \pm 1.2$ to $10.9 \pm 0.9$ points; $p<0.001$ ) was maintained for over 30 days (BEFORE to FOLLOW-UP; reduction from $15.6 \pm 1.2$ to $10.8 \pm 0.9$ points; $p<0.001$ ), showing no significant differences between END and FOLLOW-UP.

\section{Motor Examination (MDS-UPDRS Part III)}

A strong correlation between time $(F=24.97 ; p<0.0001)$ and motor MDS-UPDRS (Figure 1C) was found. Motor symptoms decreased over time and reached significance at the MID and END time-points compared to BEFORE [37.0 \pm 2.3 (BEFORE) to $34.0 \pm 2.5$ (MID) to $28.5 \pm 2.3$ (END); $p<0.001]$. At FOLLOW-UP patients demonstrated a significant decrease
$(F=11.09 ; p<0.0001)$ between BEFORE and END $(p<0.001)$, BEFORE and FOLLOW-UP $(p<0.001)$, and between END and FOLLOW-UP $(p<0.05)$, decreasing from $33.1 \pm 2.6$ (BEFORE) to $24.8 \pm 2.2$ (END) and to $21.0 \pm 2.2$ (FOLLOW-UP). There was a tendency for further improvement after treatment, but no significant differences between END and FOLLOW-UP (Figure 1G). In summary, dTMS treatment correlated with a decrease of 8.3 points in the UPDRS-III at END and 12.1 points at 30 days FOLLOW-UP. Thus, dTMS was a strong predictor for a decrease in PD motor symptoms.

\section{Motor Complications (MDS-UPDRS Part IV)}

In the present study, patients showed a significant decrease $(F=5.35 ; p<0.01)$ in motor complications. A significant difference was found between BEFORE and MID as well as between BEFORE and END (Figure 1D), from $5.3 \pm 0.7$ (BEFORE) to $4.3 \pm 0.5(\mathrm{MID})$ to $4.2 \pm 0.5$ (FOLLOW-UP) points $(p<0.05$; $p<0.01)$. Patients who participated in the follow-up session (Figure 1H) showed similar significant symptom improvements $(F=4.99 ; p<0.01)$ with a significant difference between BEFORE and END (reduction from $5.8 \pm 0.7$ to $4.1 \pm 0.5$ points; $p<0.05$ ) and a similar decrease between BEFORE and FOLLOW-UP (reduction from $5.8 \pm 0.7$ to $4.5 \pm 0.6$ points), which was not found to be significant. There were no significant differences between END and FOLLOW-UP.

\section{UP\&GO}

As can be seen in Figure 2A the treatment was a significant predictor of improvement in the UP\&GO test, as demonstrated by the decrease in the time required to complete the task $(F=0.1777$; $p<0.05)$, from BEFORE to END (17.0 $\pm 3.7-9.7 \pm 0.4)$. No differences between BEFORE to MID or from MID to END were found. Interestingly, improvements were correlated with greater severity $\left(R^{2}=0.8341\right)$ (Figure $2 B$ ), although this result may be explained by a ceiling effect, as patients cannot improve beyond
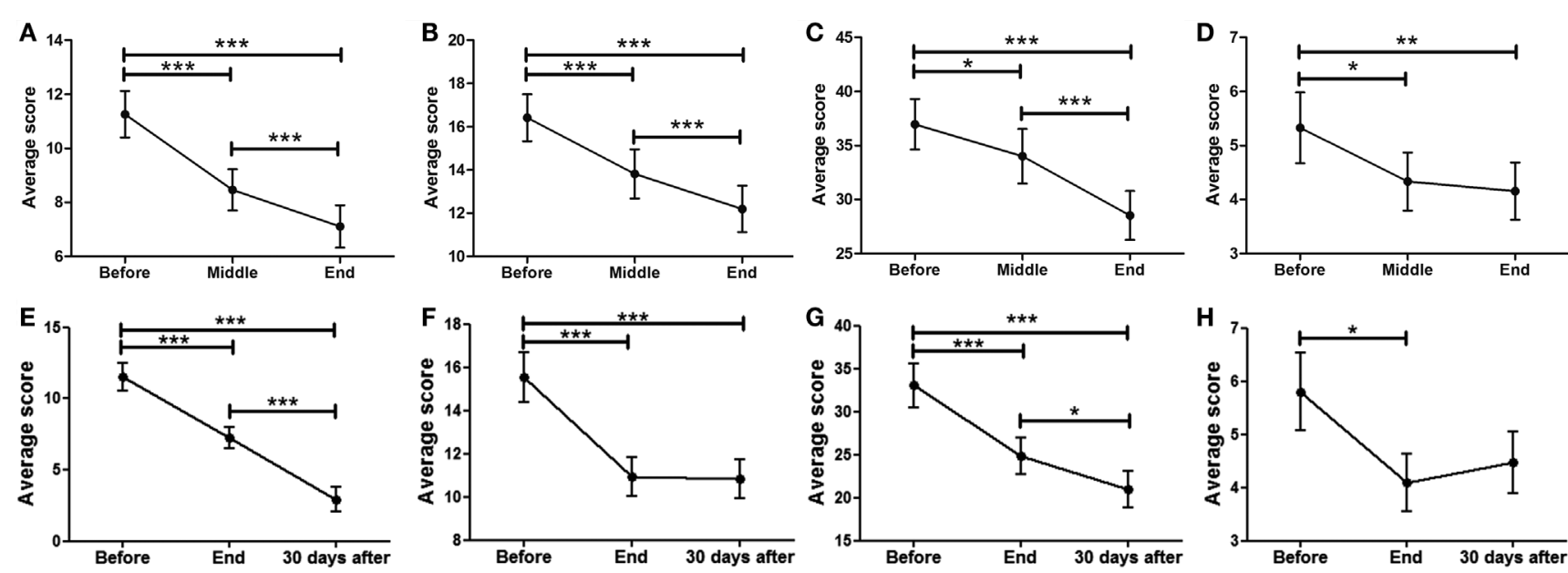

FIGURE 1 | Effects of dTMS in PD measured using the MDS-UPDRS scale. dTMS produced significant improvements in non-motor ADL (A) and motor ADL (B) at Middle and End of treatment. (C) dTMS produced a decrease in motor examination (MDS-UPDRS Part III), with a significant reduction at the End of treatment. (D) dTMS induced an improvement in motor complications that was significant at the End of treatment. Similar results are shown in a group of patients with 30-day Follow-up, in non-motor ADL (E), motor ADL (F), motor examination (G) and motor complications (H), where a significant difference was found in all measures. $\left({ }^{*} p<0.05 ;{ }^{* *} p<0.01 ;{ }^{* \star *} p<0.001\right)$. 

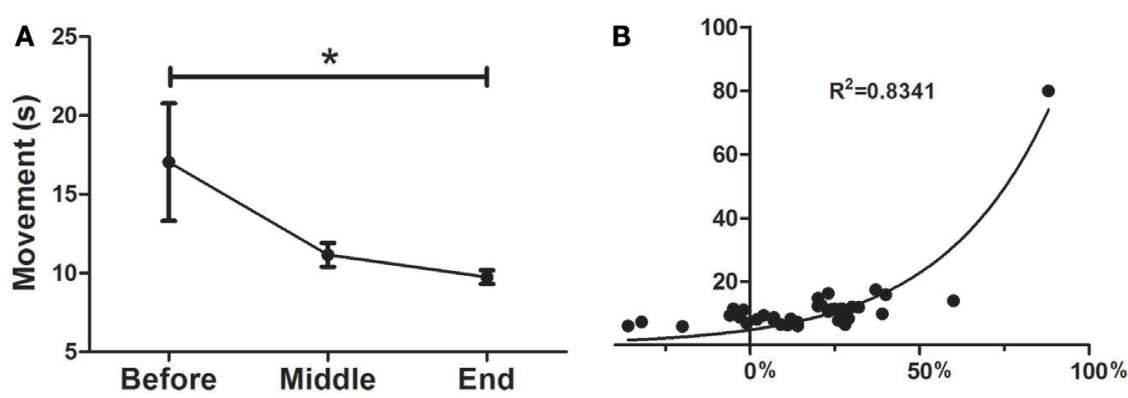

FIGURE 2 | Effects of dTMS on gait speed (UP\&GO). (A) dTMS produced a significant decrease in the time taken to stand up and walk 3 m, which was significant at the End of treatment, (B) The greater the severity in the UP\&GO, the greater the improvements after treatment. A correlation was found between initial time in seconds ( $y$ axis) and the percentage of Deep TMS improvement (initial/final time, $x$ axis). Regression shows that the higher the severity, the greater the improvements $\left({ }^{*} p<0.05\right)$
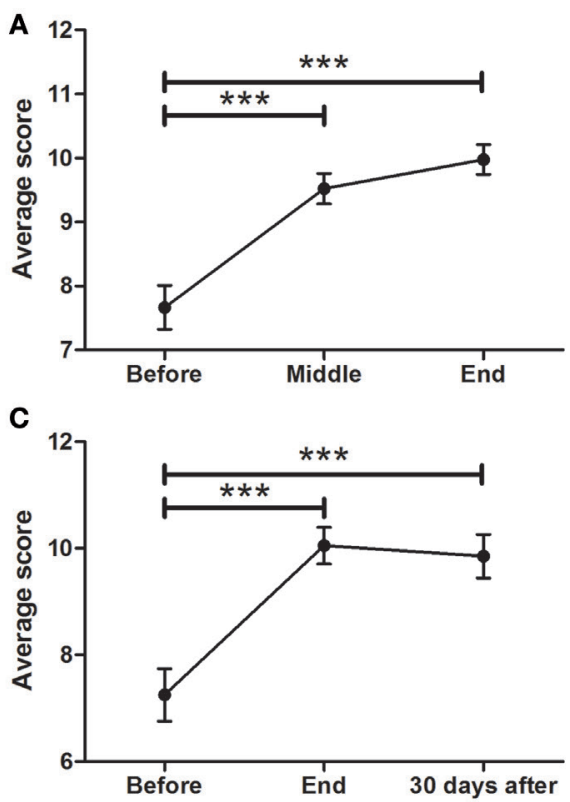

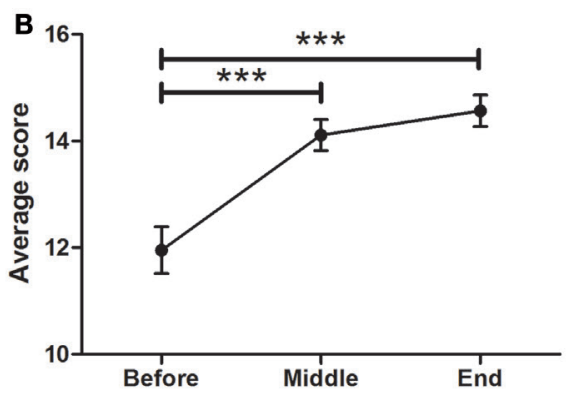

D

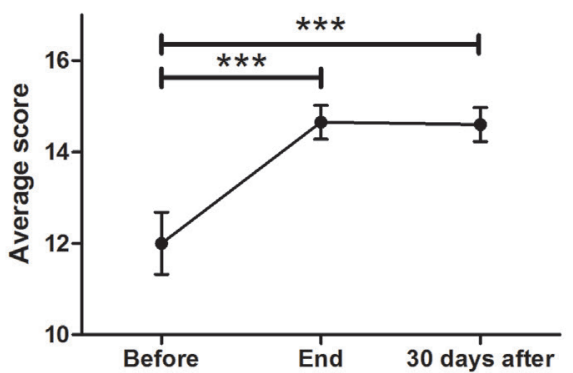

FIGURE 3 | Effects of dTMS on posture and balance (TINETTI). dTMS produced a significant improvement in posture and balance during gait (A) and while standing (B) at the END of the treatment, which were also significant for balance during gait (C) and while standing (D) at FOLLOW-UP (30 days after) ( $\left.{ }^{* \star *} p<0.001\right)$.

normality, so patients with larger symptom severity will improve more to reach normality than those with less severity.

\section{TINETTI}

Patients showed a significant difference in gait balance throughout treatment (Figure 3A; $F=19.67 ; p<0.0001$ ), increasing from $7.6 \pm 0.3$ points at BEFORE to $9.5 \pm 0.2$ at $\operatorname{MID}(p<0.0001)$, and to $10.0 \pm 0.2$ at $\operatorname{END}(p<0.0001)$. In addition, there were significant differences in static balance (Figure 3B; $F=38.48, p<0.0001$ ), increasing from $12.0 \pm 0.3$ points at BEFORE, to $14.1 \pm 0.3$ at $\operatorname{MID}(p<0.0001)$, and to $14.5 \pm 0.3$ at $\operatorname{END}(p<0.0001)$.

The improvement in gait balance was maintained at the 30-day follow-up session (Figure 3C; $F=13.96 ; p<0.0001$ ), with significant differences between BEFORE and END (7.3 $\pm 0.5-$ $10.1 \pm 0.3 ; p<0.0001)$, and between BEFORE and FOLLOW-UP
$(7.3 \pm 0.5-9.9 \pm 0.4)$. Same was found for static balance (Figure 3D; $F=4.066 ; p<0.0001)$, in which significant differences between BEFORE and END $(12.0 \pm 0.7-14.7 \pm 0.4)$ and between BEFORE and FOLLOW-UP $(12.0 \pm 0.7-14.6 \pm 0.4)$ were found.

\section{SCOPA-AUT}

As depicted in Figure 4A $(p<0.0001)$, a significant decrease in SCOPA was found between BEFORE $(12.7 \pm 1.2)$ and END $(7.5 \pm 1.0$ points, $p<0.001)$. There was also a significant reduction in cardiovascular symptoms (Figure 4B; $p<0.0001$ ) from BEFORE $(3.6 \pm 0.5)$ to END $(1.7 \pm 0.3)$. A significant decrease in gastrointestinal symptoms was found (Figure 4C; $p<0.0001$ ) between BEFORE $(3.2 \pm 0.6)$ and END (2.0 \pm 0.3$)$. Additionally, significant decreases in urinary symptoms were found between the BEFORE and END time points (Figure 4D; from $3.2 \pm 0.5$ to 
$1.7 \pm 0.3, p<0.001)$. Thermoregulation also showed significant improvements (Figure $4 \mathrm{E}$; from $2.1 \pm 0.4$ to $1.6 \pm 0.4, p<0.001$ ) but no significant decreases in sexual symptoms were found (Figure 4F).

For patients who attended the follow-up session, the total symptom score (Figure 4G; $p<0.0001$ ), showed a significant decrease $(F=12.33 ; p<0.001)$ from BEFORE to END and from BEFORE to FOLLOW-UP $[11.9 \pm 2.0$ (BEFORE) to $6.5 \pm 1.7$ (END) to $7.1 \pm 1.5$ (FOLLOW-UP), $p<0.001$ ]. There was a significant reduction $(F=8.697 ; p<0.01)$ in cardiovascular symptoms
(Figure 4H) from BEFORE $(3.6 \pm 0.9)$ to END $(1.4 \pm 0.5)$ and to FOLLOW-UP $(1.3 \pm 0.3)$. Additionally, a significant decrease $(F=4.696 ; p<0.05)$ in gastrointestinal symptoms (Figure 4I) between BEFORE $(3.3 \pm 0.7)$ and END $(2.1 \pm 0.6)$ was found. No significant differences were found in gastrointestinal symptoms between BEFORE and FOLLOW-UP. Urinary symptoms showed a significant decrease at END $(F=3.575 ; p<0.05)$ but not at FOLLOW-UP (Figure 4J; from $2.8 \pm 0.7$ to $1.4 \pm 0.6$ ). There was a non-significant tendency to improve in both thermoregulation (Figure 4K) and sexual symptoms (Figure 4L).
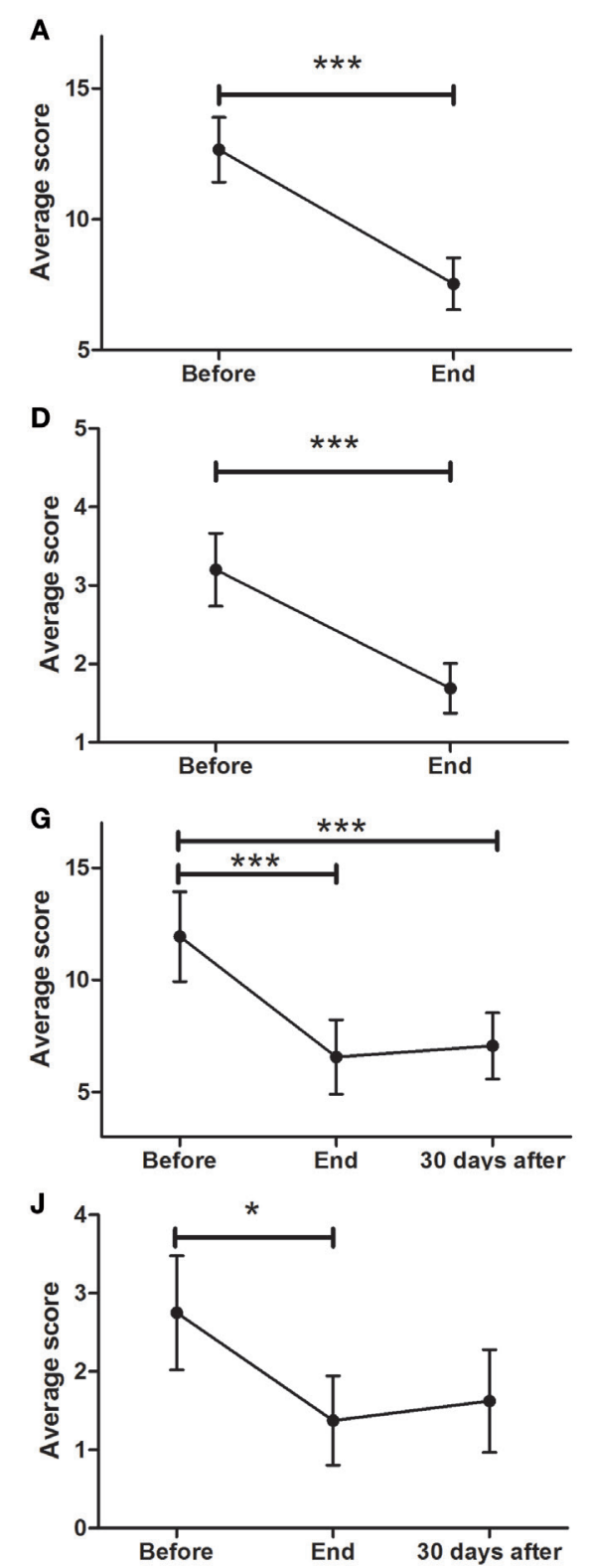
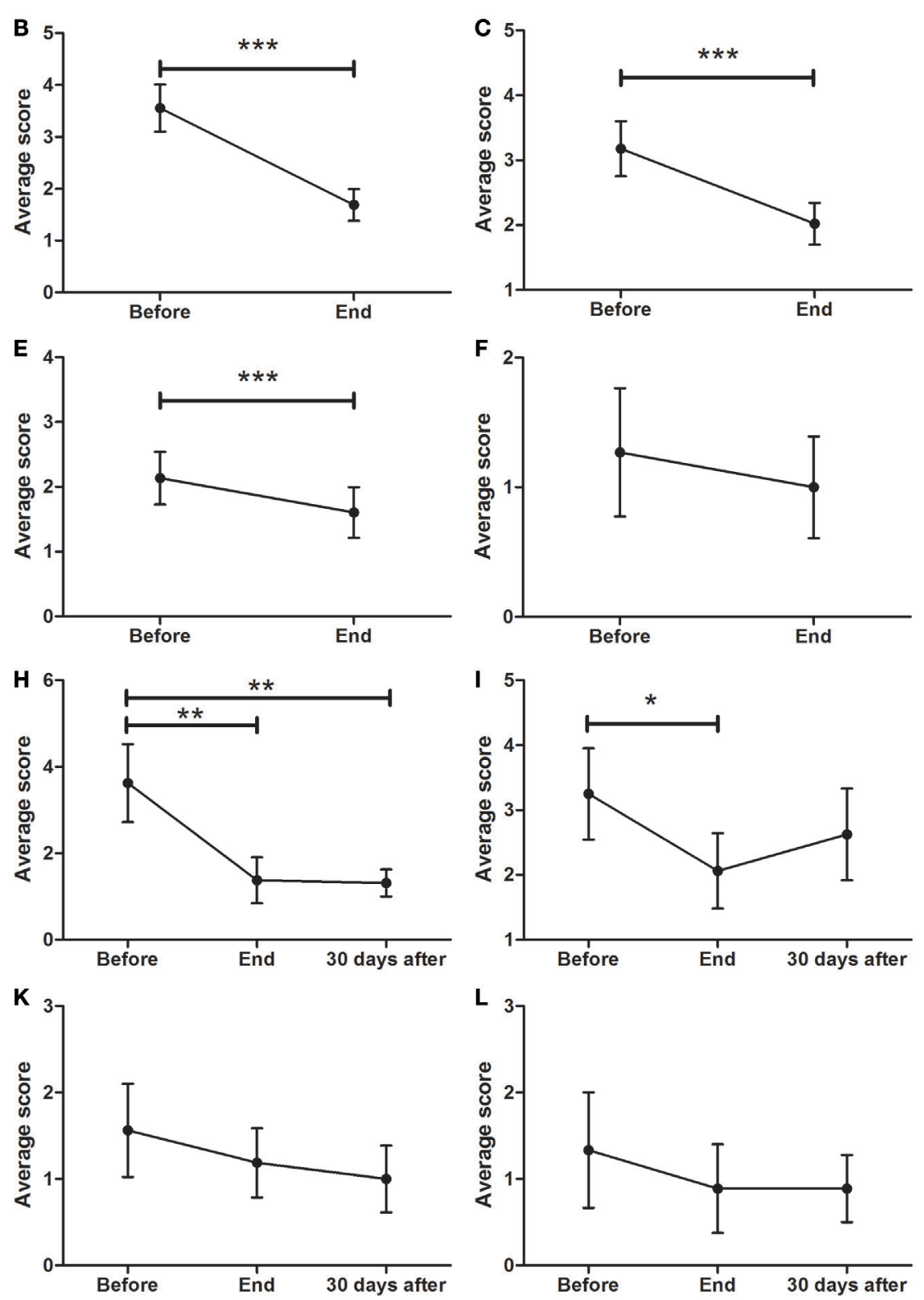

FIGURE 4 | Effects of dTMS effects on autonomic symptoms as measured by SCOPA. (A) dTMS produced significant improvements in total SCOPA at END. dTMS also induced significant improvements in cardiovascular (B), gastrointestinal (C), urinary (D), and thermoregulation (E) from BEFORE to END, but non-significant reductions in (F) sexual symptoms. Significant differences were found at the Follow-up period for Total SCOPA (G) and cardiovascular symptoms (H), but not for gastrointestinal $\mathbf{( I )}$, urinary $\mathbf{( J )}$, thermoregulation $\mathbf{( K )}$ and sexual Symptoms (L) $\left({ }^{\star} p<0.05 ;{ }^{\star \star} p<0.01 ;{ }^{\star \star \star} p<0.001\right)$. 


\section{ON/OFF Daily Periods}

Patients were asked to self-assess their daily symptoms and to measure ON \& OFF periods every $30 \mathrm{~min}$, from 1 week prior to treatment (BEFORE), until its end (END). Fourteen patients completed the assessment ( $31 \%$ of the patients). There was a significant increase in percentage of $\mathrm{ON}$ time, from $32.0 \pm 0.8$ to $48.0 \pm 8.4 \% / \mathrm{h}$ (see Figure $5 \mathbf{A} ; F=7.619, p<0.001$ ) and a significant decrease in OFF-time from $68.1 \pm 8.0$ to $52.0 \pm 8.0 \% / \mathrm{h}$ (see Figure 5B; $F=18.96, p<0.001$ ). The increase from 32 to $48 \%$ of ON time per hour means a $50 \%$ increase in ON time each hour. In terms of $\mathrm{ON}$ hours per day, patients increased from $4.4 \pm 1.2$ to $7.6 \pm 1.2 \mathrm{~h} /$ day, which corresponds to a $73 \%$ increase in total ON time per day.

\section{Hamilton Rating Scale for Depression (HDRS ${ }_{21}$ )}

Of the 45 patients, $29(64.4 \%)$ scored 7 or more points on the $H D R S_{21}$. This means that 29 patients in the sample were considered depressed as defined by the physician-applied $H D R S_{21}$ (Hamilton) scale. As seen in Figure 6A, there was a significant improvement in overall depressive symptoms of all patients, with a significant effect of time $(F=27.64 ; p<0.0001)$. There was a significant decrease in depressive symptoms from BEFORE $(11.3 \pm 1.1$ points $)$ to $\mathrm{END}(5.5 \pm 0.9 ; p<0.0001)$, improvement that was maintained at FOLLOW-UP $(5.6 \pm 0.7 ; p<0.05)$ (Figure 6B). Analysis of depressed patients only ( $\geq 7$ points) showed a significant symptom decrease (F014.55; $p<0.0001)$ from BEFORE $(12.9 \pm 0.9$ points $)$ to $\mathrm{END}(5.6 \pm 1.1 ; p<0.001)$ in the HDRS scale. At the END time point, $62 \%$ of depressed patients experienced symptom remission ( $<7$ points).

\section{Beck Depression Inventory}

To compare the results of health professional-applied HDRS with a self-applied depression scale, the BDI was used. Consistent with the results found with the HDRS scale, there was also a significant effect of time in depressive symptoms as evaluated by the self-assessed BDI scale $(F=25.65 ; p<0.0001)$, with a significant decrease from $10.7 \pm 1.2$ at the BEFORE to $5.4 \pm 0.9$ at the END point (Figure $6 \mathrm{C}$ ). This improvement was maintained at the 30 days FOLLOW-UP evaluation $[F=9.539$ : $p<0001$; from $9.1 \pm 1.6$ (BEFORE) to $6.3 \pm 1.5$ (FOLLOW-UP)] (Figure 6D).

\section{Motor Improvements in Depressed and Non-Depressed Patients}

To determine whether antidepressant effects may have contributed to the improvements in motor symptoms, patients' data were divided into two groups; those that did not have depression ( $<7$ points) and those that had depression ( $\geq 7$ points) as assessed by the HDRS ${ }_{21}$ scale. Twenty-five patients showed depression and 20 were not depressed according to the $\mathrm{HDRS}_{21}$ scale. Their data from the motor MDS-UPDRS (Part III) subscale were compared within each group and between groups. A strong correlation between time and motor MDS-UPDRS (Figure 7A) was found for both the depressed $(F=28.53$; $p<0.0001)$ and the non-depressed groups $(F=14.55 ; p<0.0001)$. For the depressed group, motor symptoms decreased over time and reached significance at the MID and END time-points compared to BEFORE $[19.1 \pm 1.6$ (BEFORE) to $16.24 \pm 1.7$ (MID) to $14.8 \pm 1.7$ (END); $p<0.001]$. For the non-depressed group, motor symptoms decreased over time and reached significance at the MID and END time-points compared to BEFORE $[13.1 \pm 1.1$ (BEFORE) to $10.8 \pm 1.0$ (MID) to $9.0 \pm 0.8$ (END); $p<0.001]$. Note that depressed patients showed greater symptom severity compared to non-depressed patients, at BEFORE $(p<0.001)$, MIDDLE $(p<0.001)$, and END $(p<0.001)$ time points. The improvements in both groups in response to treatment were almost identical (Figure 7B), showing no significant differences between them (depressed patients, $4.3 \pm 0.6$ points; non-depressed patients, $4.3 \pm 0.9$ points). In consequence, dTMS improvements in motor symptoms were significant and similar irrespective of whether patients were depressed or not at the beginning of treatment.

\section{Correlations Between Gender, Physical Activity, Severity, and Improvements}

Multivariate analysis using the Spearman test showed significant correlations between age and initial values of disease severity (MDS-UPDRS motor, non-motor ADL, motor ADL, complications of treatment, UP\&GO, and Tinetti). Disease severity according to the H\&Y, was correlated with years of disease. Another correlation was found between initial HDRS and both MDS-UPDRS treatment complications and Tinetti. Lastly, a correlation was found between HDRS and ADL at the END time
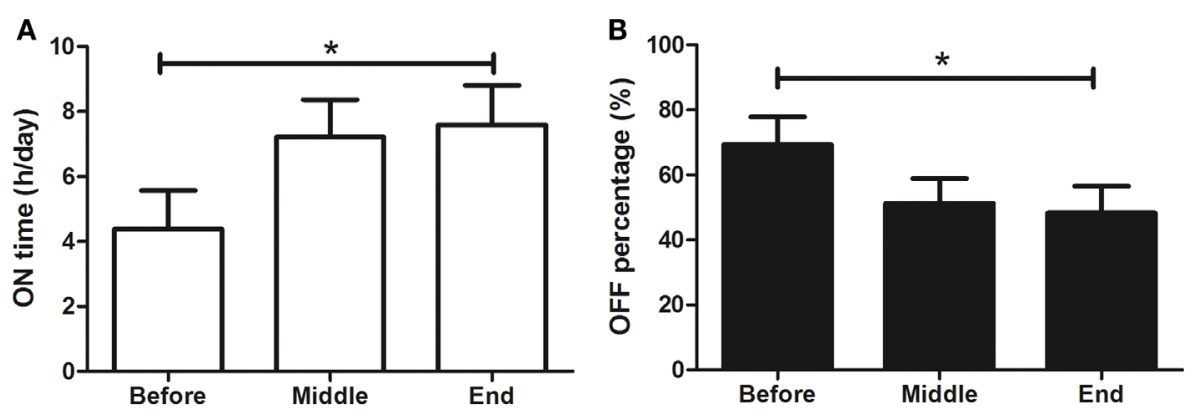

FIGURE 5 | Effects of dTMS on OFF and ON daily periods. dTMS produced (A) a significant increase of ON time per day and (B) a significant decrease in OFF time per hour $\left({ }^{*} p<0.05\right)$ 

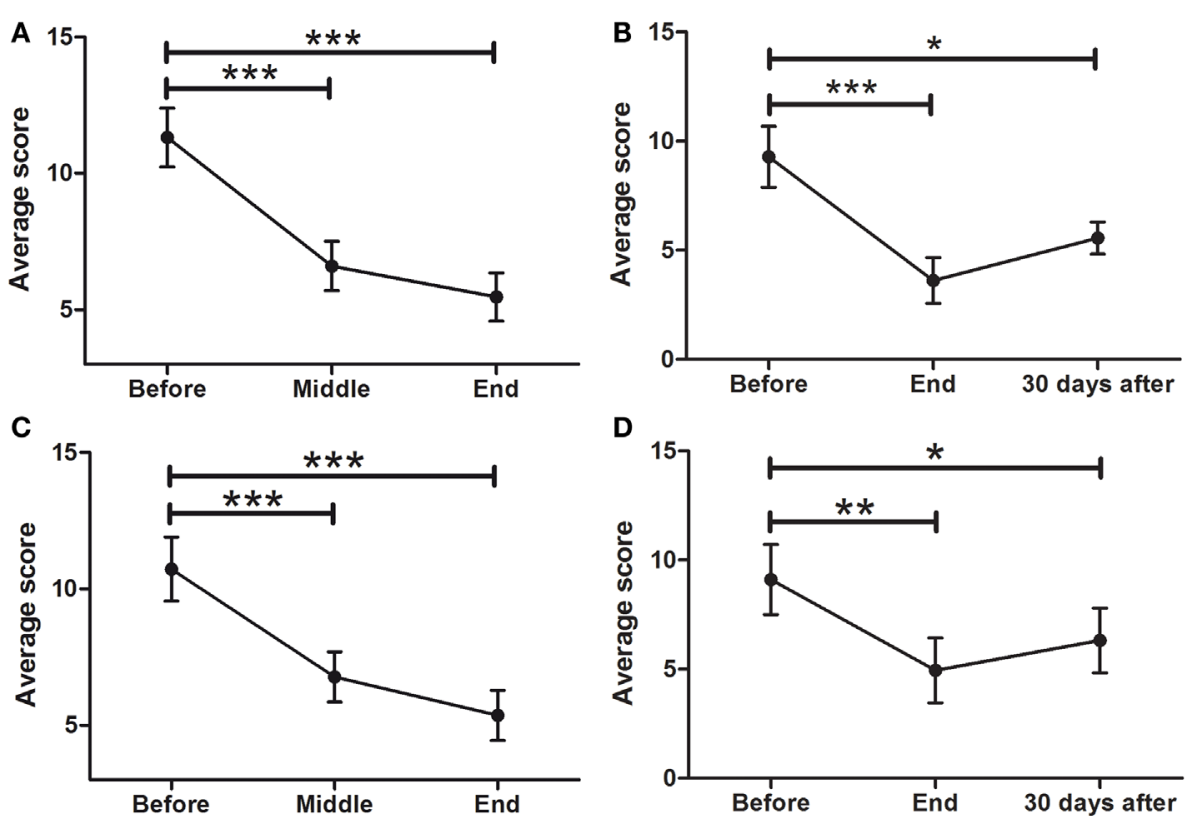

FIGURE 6 | Effects of dTMS on depressive symptoms as measured by Hamilton (HDRS ${ }_{21}$ ) and Beck Depression Inventory (BDI). dTMS produced a significant improvement in depressive symptoms, leading to remission ( $<7$ points) according to HDRS at the END (A) and the FOLLOW-UP (B) of the treatment. The same results were found with the BDI at the same points [(C) for END and (D) for FOLLOW-UP] $\left({ }^{*} p<0.05 ;{ }^{* *} p<0.01 ;{ }^{* \star *} p<0.001\right)$.
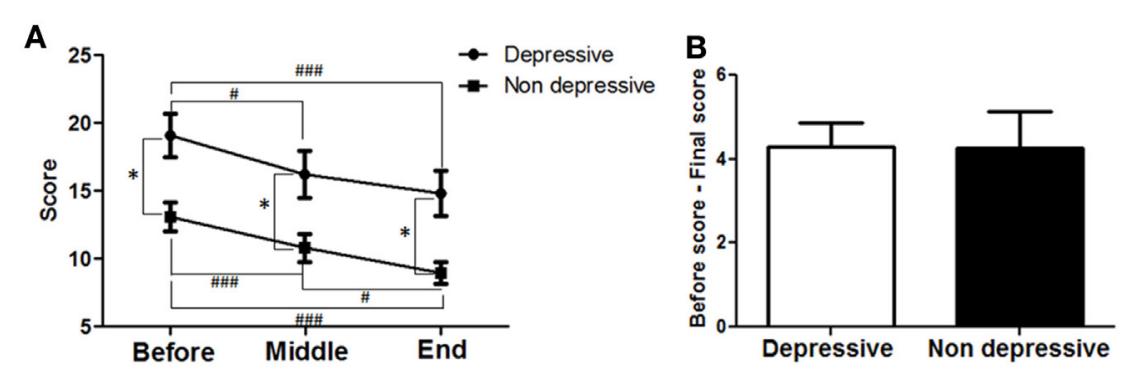

FIGURE 7 | Effects of dTMS on motor symptoms depending on previous depression as measured by Hamilton (HDRS ${ }_{21}$ ). (A) dTMS produced significant and similar improvements in motor symptoms in patients with ( $\geq 7$ points) or without ( $<7$ points) depression according to HDRS score obtained at the BEFORE session. (B) Difference between BEFORE and END in both groups was similar in value and not different statistically $\left({ }^{*} p<0.05\right.$; ${ }^{* *} p<0.01$; ${ }^{* \star *} p<0.001$ and \#p $<0.05 ; \# p<0.01 ; \#$ \#\# $<0.001)$.

point. The variables age, years of disease or number of sessions treated did not correlate with physical activity. For details see Table 4.

\section{Discussion}

The present study supports the notion that dTMS could be a safe and effective adjuvant treatment for PD, yet given the lack of a placebo-controlled group, the present study cannot be considered a demonstration of treatment efficacy. However, the efficacy of low frequency stimulation of the motor cortex with rTMS has been demonstrated by several placebo-controlled studies, which were analyzed in a recent meta-analysis (22).

This is the first study to evaluate retrospectively the effects of dTMS in a clinical setting. This is relevant because placebo-controlled studies include only a subgroup of patients with similar symptom severities, whereas in a clinical setting, patients treated show more heterogeneous symptoms, ages, and demographics. The present results, based on a cohort of 45 patients, demonstrate that dTMS using LF stimulation of the M1, and $\mathrm{HF}$ stimulation of the PFC is a predictor to a wide range of significant improvements in PD symptoms, including not only motor symptoms, which have been reported previously in placebo-controlled studies for rTMS (22), but also in non-motor, autonomic and depressive symptoms, and significant improvements in activities of daily living (ADL). Although only 32 patients participated in the FOLLOW-UP session, their improvements remained significant 30 days after treatment (see Table 1 for a summary), suggesting that treatment effects lasted at least 30 days post-treatment. 
TABLE 4 | Spearman test for multivariate analysis.

\begin{tabular}{|c|c|c|c|c|c|c|c|c|c|c|c|c|}
\hline & Age & Gender & $\begin{array}{l}\text { Years of } \\
\text { disease }\end{array}$ & $\begin{array}{l}\text { Y\&H } \\
\text { scale }\end{array}$ & $\begin{array}{l}\text { Physical } \\
\text { activity }\end{array}$ & $\begin{array}{l}\text { Initial } \\
\text { HDRS }\end{array}$ & $\begin{array}{l}\text { Final } \\
\text { HDRS }\end{array}$ & $\begin{array}{l}\text { Initial MDS- } \\
\text { UPDRS } \\
\text { ADL }\end{array}$ & $\begin{array}{c}\text { Final MDS- } \\
\text { UPDRS } \\
\text { ADL }\end{array}$ & $\begin{array}{l}\Delta \text { MDS- } \\
\text { UPDRS } \\
\text { ADL }\end{array}$ & $\begin{array}{c}\text { Initial } \\
\text { treatment } \\
\text { complications }\end{array}$ & Sessions \\
\hline $\begin{array}{l}\text { Initial MDS-UPDRS } \\
\text { motor }\end{array}$ & - & - & - & - & - & - & - & $\star \star \star$ & 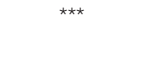 & - & 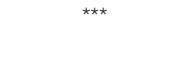 & - \\
\hline $\begin{array}{l}\text { Final MDS-UPDRS } \\
\text { motor }\end{array}$ & - & - & - & - & - & - & $\star$ & $\star \star \star \star ~$ & $\star \star \star *$ & - & * & - \\
\hline $\begin{array}{l}\Delta \text { MDS-UPDRS } \\
\text { motor }\end{array}$ & - & - & - & - & - & - & - & - & - & - & * & - \\
\hline Initial UP\&GO & - & - & - & - & - & - & - & - & - & - & - & - \\
\hline Final UP\&GO & - & - & - & - & - & - & - & - & - & - & - & - \\
\hline$\Delta$ UP\&GO & $\star \star$ & - & - & - & - & - & - & - & - & * & - & - \\
\hline Initial HDRS & - & - & - & - & - & 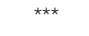 & $\star \star \star$ & - & - & - & - & - \\
\hline Final HDRS & - & - & - & - & * & 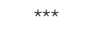 & 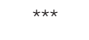 & * & ** & - & - & - \\
\hline $\begin{array}{l}\text { Initial gastrointestinal } \\
\text { SCOPA }\end{array}$ & - & - & * & - & - & - & - & - & ** & - & - & - \\
\hline $\begin{array}{l}\Delta \text { Gastrointestinal } \\
\text { SCOPA }\end{array}$ & - & - & - & - & - & - & - & - & - & - & * & - \\
\hline Initial urinary SCOPA & - & - & $\star *$ & - & - & - & - & - & * & * & - & - \\
\hline$\Delta$ Urinary SCOPA & - & - & ** & ** & - & - & - & - & - & * & - & - \\
\hline $\begin{array}{l}\text { Initial Cardiovascular } \\
\text { SCOPA }\end{array}$ & - & - & - & - & - & - & - & - & * & ** & * & - \\
\hline $\begin{array}{l}\Delta \text { Cardiovascular } \\
\text { SCOPA }\end{array}$ & - & - & - & - & - & - & - & - & - & - & - & - \\
\hline $\begin{array}{l}\text { Initial } \\
\text { Thermoregulation } \\
\text { SCOPA }\end{array}$ & * & - & - & - & - & * & * & - & - & - & * & - \\
\hline $\begin{array}{l}\Delta \text { Thermoregulation } \\
\text { SCOPA }\end{array}$ & - & - & - & - & - & - & - & - & - & - & - & - \\
\hline Initial sexual SCOPA & - & - & - & - & - & - & - & - & - & - & - & - \\
\hline$\Delta$ Sexual SCOPA & - & - & * & - & - & - & - & - & - & - & - & - \\
\hline Initial Total SCOPA & - & - & - & - & - & - & $\star$ & - & ** & - & 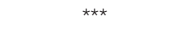 & - \\
\hline$\Delta$ Total SCOPA & - & - & - & - & * & - & - & - & - & - & - & - \\
\hline Initial gait tinetti & - & - & - & - & - & - & - & - & - & - & - & - \\
\hline$\Delta$ gait tinetti & - & - & - & - & - & - & * & - & - & - & - & - \\
\hline Initial static tinetti & - & - & - & - & - & * & - & - & - & * & * & - \\
\hline$\Delta$ static tinetti & - & - & - & - & - & - & - & - & - & - & ** & - \\
\hline
\end{tabular}

Correlations are shown as "**; no correlation as "-" (" $p<0.05$; ** $\left.p<0.01 ;{ }^{* * *} p<0.001\right)$.

In the recently published meta-analysis that included eight placebo-controlled trials, LF rTMS was reported to be an effective adjuvant for the treatment of motor symptoms in PD, with an average improvement of 5.05 points in the UPDRS part III (22). In the present study, the average decrease in motor symptoms according to the MDS-UPDRS part III subscale was 8.5 points at the END of treatment and 8.6 points 30 days after treatment. The UPDRS is among the most accepted scales available for PD symptom evaluation (29).

Perhaps one of the most important results of the present study is the wide range of symptoms that benefit from dTMS treatment, suggesting that the improvements are not only limited to the motor symptoms included in MDS-UPDRS (III). This suggests that other symptoms could be measured in clinical trials assessing dTMS for PD treatment. For example, the risk of fall, which is common in PD patients and may lead to the need of a walking aid, significantly decreased thereby rendering those aids unnecessary in several patients, affording them the ability, for example, to climb stairs safely.

The present results also suggest that patients benefit from treatment irrespective of disease severity, especially when measuring improvements in the UP\&GO scale [which measures gait speed (32)]. The improvements in response to treatment were larger for patients with greater severity, which may be explained by a ceiling effect, as patients with low disease severity have fewer symptoms and thus, less potential for improvement to reach normality, than those suffering from greater disease severity. It is interesting to note that, previous studies using fMRI have shown that rTMS-related improvements in mid-gait freezing are correlated with increased caudate activity and with changes in functional connectivity between PFC and supplementary motor area (9). 
The present improvements in autonomic symptoms as measured by SCOPA are consistent with previous studies showing that LF rTMS in M1 or HF in PFC may affect the autonomic system (38), whereas HF in PFC may improve autonomic cardiac dysfunctions linked to depression (39). Our findings further support a possible relationship between the autonomic system and LF rTMS in M1 or HF in PFC.

In terms of depressive symptoms, the self-administered BDI scale was used to contrast patients' self-perception of mood and depressive symptoms, with clinician-applied HDRS ${ }_{21}$. Both scales revealed significant improvements, reaching remission in $62 \%$ of depressed patients (18 out of 29 depressed patients). This antidepressant effect may be the result of motor symptom improvement, as the multivariate analysis showed a correlation between HDRS and ADL at END, suggesting that greater improvements in ADL may lead to greater improvements in depression. However, a previous clinical trial evaluated the benefit of rTMS in PD patients with depressive symptoms, with HF stimulation targeting the left PFC (40) to obtain antidepressant effects. Thus, it is also possible that in the present study the bilateral HF stimulation of PFC contributed to the treatment antidepressant effects.

This raises the question of whether the improvements in motor symptoms obtained here after dTMS can be attributed to antidepressant effects. To answer this question, we compared the improvement of patients that initiated the treatment with and without depression. Our results show that although depressed patients show in average greater motor symptom severity, their improvements are similar to those obtained in patients without depression, at least for the motor UPDRS. This suggests that motor symptom improvements after dTMS are significant and similar irrespective of depressive symptoms. This does not rule out a contribution of antidepressant effects, but demonstrates that motor symptom improvements after dTMS cannot be attributed to antidepressant effects, as patients without depression have similar symptom improvements as those with depression.

Two key factors to be considered in PD studies are time of day and the patients' emotional state when symptoms are being measured. In this study, measurements could not be performed during OFF periods as patients ranged from those experiencing $<10 \%$ of the day OFF, to those experiencing full day OFF. Patients with $100 \%$ OFF response to Levodopa were included in the present study only if diagnosed with PD and had been responsive to the drug earlier in their disease. Measurements were taken at the same time of day in all patients, during an ON period, unless the patient experienced no ON periods, in which case measurements were taken at the time most comfortable to the patient. To ensure that measurements did reflect the patient's motor symptoms throughout the day, they were given a self-applied scale for ON\&OFF periods with questions to be answered every $30 \mathrm{~min}$. Adherence to scale completion reached $30 \%$, and resulted in two major findings. First, there was a significant and large increase in daily $\mathrm{ON}$ time, incrementing from $4.4 \pm 1.2$ to $7.6 \pm 1.2 \mathrm{~h} /$ day, a $42 \%$ increase. Second, 5 patients began treatment with $100 \%$ OFF time (without ON time) and by the end of treatment, 3 of those patients had gained ON periods, increasing in average from 0 to $6.3 \mathrm{~h} /$ day. This implies that there was a significant improvement in the amount of ON hours per day independently of the time of measurement, suggesting that dTMS may potentiate the effect of Levodopa. There were no changes in pharmacotherapy before or during treatment. Although dyskinesia decreased in average during treatment, four patients showed increased dyskinesia after treatment. We were able to control this increase by decreasing levodopa dosage post-treatment. In consequence, it may be proposed that dTMS treatment potentiates the effects of levodopa, which in some cases may lead to a decrease in the necessary levodopa dose and may control the medication's complications. No matter how suggestive these results may seem, a placebocontrolled, double blind study should be performed, specially designed to determine the efficacy of treatment in non-motor symptoms and to assess the possibility that treatment potentiates levodopa effects.

The present study has several limitations; it is a retrospective evaluation of clinical efficacy, which means it is a compilation of 45 clinical cases on the effects of dTMS for the treatment of PD symptoms. Thus, there was no control group to measure the placebo effect and therefore it was not "blinded." This lack of placebo control is important. Previous studies have shown that significant dopamine release may occur when the declared probability of receiving active treatment was above $75 \%$, concluding that the strength of belief of improvement can directly modulate dopamine release in patients with PD (41). Placebo responses in PD have been reported with a magnitude between 9 and $59 \%$ of that of the active drug group (42), or 7-10\% of symptom relief (43), as well as subjective and short lasting, not measured consistently by currently used scales (44). Although the present study does not have a placebo control group, the treatment with LF rTMS of motor cortex has been shown to be effective against placebo in a series of randomized placebo-controlled clinical trials reviewed by Zhu and colleagues (22). The above placebo-controlled studies were designed to assess improvements in motor symptoms using UPDRS and were not designed to test non-motor symptoms, which according to the present study, may also show improvements in response to treatment.

The SCOPA, MDS-UPDRS, and TINETTI scales used here are widely accepted and used in previous studies. The multivariate analysis showed correlations between initial values of the scales used (MDS-UPDRS, SCOPA, TINETTI) and disease severity and years of disease, as well as a correlation between ADL, SCOPA, and depression. All those correlations indirectly validate the scales used, as such correlations are expected; for example, ADL should correlate with depression, and motor exploration should correlate with disease severity. Expected correlations were also found between disease severity and years with disease, in addition to a correlation between ADL, SCOPA, and depression.

A few interesting results were found using the Spearman test. First, there was a correlation between physical activity and both the score in HDRS at the END and the difference (improvement) in the total SCOPA score. By contrast, gender or physical activity did not correlate neither with disease severity or treatment results, whereas patients who exercise may improve more in autonomic symptoms and end treatment with greater improvements in depression. 
An issue that cannot be readily assessed in the present study is the duration of the improvements. The present results suggest that benefits from treatment last for at least 30 days. However, a placebo-controlled study is required to assess the duration of dTMS effects in PD.

In conclusion, dTMS is a strong predictor of improvements in PD symptoms. In our cohort of 45 patients, dTMS treatment induced significant improvements in motor and non-motor symptoms, ADL, gait, posture, balance, risk of fall, gait speed, autonomic and depressive symptoms, as well as a $42 \%$ increase in $\mathrm{ON}$ hours per day. Improvements were independent of

\section{References}

1. Pascual-Leone A, Valls-Sole J, Brasil-Neto JP, Cammarota A, Grafman J, Hallett M. Akinesia in Parkinson's disease. II. Effects of subthreshold repetitive transcranial motor cortex stimulation. Neurology (1994) 44:892-8. doi:10.1212/WNL.44.5.892

2. Pascual-Leone A, Valls-Sole J, Wassermann EM, Hallett M. Responses to rapid-rate transcranial magnetic stimulation of the human motor cortex. Brain (1994) 117(Pt 4):847-58. doi:10.1093/brain/117.4.847

3. Pell GS, Roth Y, Zangen A. Modulation of cortical excitability induced by repetitive transcranial magnetic stimulation: influence of timing and geometrical parameters and underlying mechanisms. Prog Neurobiol (2011) 93:59-98. doi:10.1016/j.pneurobio.2010.10.003

4. Siebner HR, Rossmeier C, Mentschel C, Peinemann A, Conrad B. Short-term motor improvement after sub-threshold 5-Hz repetitive transcranial magnetic stimulation of the primary motor hand area in Parkinson's disease. J Neurol Sci (2000) 178:91-4. doi:10.1016/S0022-510X(00)00370-1

5. Khedr EM, Farweez HM, Islam H. Therapeutic effect of repetitive transcranial magnetic stimulation on motor function in Parkinson's disease patients. Eur J Neurol (2003) 10:567-72. doi:10.1046/j.1468-1331.2003.00649.x

6. Lefaucheur JP, Drouot X, Von Raison F, Menard-Lefaucheur I, Cesaro P, Nguyen JP. Improvement of motor performance and modulation of cortical excitability by repetitive transcranial magnetic stimulation of the motor cortex in Parkinson's disease. Clin Neurophysiol (2004) 115:2530-41. doi:10.1016/j. clinph.2004.05.025

7. Fregni F, Simon DK, Wu A, Pascual-Leone A. Non-invasive brain stimulation for Parkinson's disease: a systematic review and meta-analysis of the literature. J Neurol Neurosurg Psychiatry (2005) 76:1614-23. doi:10.1136/ jnnp.2005.069849

8. Elahi B, Elahi B, Chen R. Effect of transcranial magnetic stimulation on Parkinson motor function - systematic review of controlled clinical trials. Mov Disord (2009) 24:357-63. doi:10.1002/mds.22364

9. Gonzalez-Garcia N, Armony JL, Soto J, Trejo D, Alegria MA, Drucker-Colin R. Effects of rTMS on Parkinson's disease: a longitudinal fMRI study. J Neurol (2011) 258:1268-80. doi:10.1007/s00415-011-5923-2

10. Speer AM, Kimbrell TA, Wassermann EM, D Repella J, Willis MW, Herscovitch $\mathrm{P}$, et al. Opposite effects of high and low frequency rTMS on regional brain activity in depressed patients. Biol Psychiatry (2000) 48:1133-41. doi:10.1016/ S0006-3223(00)01065-9

11. Kito S, Fujita K, Koga Y. Changes in regional cerebral blood flow after repetitive transcranial magnetic stimulation of the left dorsolateral prefrontal cortex in treatment-resistant depression. J Neuropsychiatry Clin Neurosci (2008) 20:74-80. doi:10.1176/appi.neuropsych.20.1.74

12. Speer AM, Benson BE, Kimbrell TK, Wassermann EM, Willis MW, Herscovitch P, et al. Opposite effects of high and low frequency rTMS on mood in depressed patients: relationship to baseline cerebral activity on PET. J Affect Disord (2009) 115:386-94. doi:10.1016/j.jad.2008.10.006

13. Kleine BU, Praamstra P, Stegeman DF, Zwarts MJ. Impaired motor cortical inhibition in Parkinson's disease: motor unit responses to transcranial magnetic stimulation. Exp Brain Res (2001) 138:477-83. doi:10.1007/s002210100731

14. Lefaucheur JP. Motor cortex dysfunction revealed by cortical excitability studies in Parkinson's disease: influence of antiparkinsonian treatment and cortical stimulation. Clin Neurophysiol (2005) 116:244-53. doi:10.1016/j. clinph.2004.11.017 subjacent depression. These findings suggest that dTMS may be an effective add-on for the treatment of PD. A placebo-controlled trial analyzing the effects of dTMS on these symptoms need follow this study to demonstrate the efficacy of dTMS in PD and possible synergic effects with concomitant dopaminergic treatment.

\section{Acknowledgments}

We wish to thank all the patients who participated in this study and their treating physicians.

15. Cantello R, Tarletti R, Varrasi C, Cecchin M, Monaco F. Cortical inhibition in Parkinson's disease: new insights from early, untreated patients. Neuroscience (2007) 150:64-71. doi:10.1016/j.neuroscience.2007.08.033

16. Chu J, Wagle-Shukla A, Gunraj C, Lang AE, Chen R. Impaired presynaptic inhibition in the motor cortex in Parkinson disease. Neurology (2009) 72:842-9. doi:10.1212/01.wnl.0000343881.27524.e8

17. Todd G, Taylor JL, Baumann D, Butler JE, Duma SR, Hayes M, et al. Substantia nigra echomorphology and motor cortex excitability. Neuroimage (2010) 50:1351-6. doi:10.1016/j.neuroimage.2010.01.088

18. Mally J, Stone TW. Improvement in Parkinsonian symptoms after repetitive transcranial magnetic stimulation. J Neurol Sci (1999) 162:179-84. doi:10.1016/S0022-510X(98)00318-9

19. Kozel FA, Tian F, Dhamne S, Croarkin PE, Mcclintock SM, Elliott A, et al. Using simultaneous repetitive transcranial magnetic stimulation/ functional near infrared spectroscopy (rTMS/fNIRS) to measure brain activation and connectivity. Neuroimage (2009) 47:1177-84. doi:10.1016/j. neuroimage.2009.05.016

20. Filipovic SR, Rothwell JC, Bhatia K. Low-frequency repetitive transcranial magnetic stimulation and off-phase motor symptoms in Parkinson's disease. J Neurol Sci (2010) 291:1-4. doi:10.1016/j.jns.2010.01.017

21. Filipovic SR, Rothwell JC, Bhatia K. Slow $(1 \mathrm{~Hz})$ repetitive transcranial magnetic stimulation (rTMS) induces a sustained change in cortical excitability in patients with Parkinson's disease. Clin Neurophysiol (2010) 121:1129-37. doi:10.1016/j.clinph.2010.01.031

22. Zhu H, Lu Z, Jin Y, Duan X, Teng J, Duan D. Low-frequency repetitive transcranial magnetic stimulation on Parkinson motor function: a meta-analysis of randomised controlled trials. Acta Neuropsychiatr (2015) 27:82-9. doi:10.1017/neu.2014.43

23. Del Olmo MF, Bello O, Cudeiro J. Transcranial magnetic stimulation over dorsolateral prefrontal cortex in Parkinson's disease. Clin Neurophysiol (2007) 118:131-9. doi:10.1016/j.clinph.2006.09.002

24. Strafella AP, Paus T, Barrett J, Dagher A. Repetitive transcranial magnetic stimulation of the human prefrontal cortex induces dopamine release in the caudate nucleus. J Neurosci (2001) 21:RC157.

25. Roth Y, Amir A, Levkovitz Y, Zangen A. Three-dimensional distribution of the electric field induced in the brain by transcranial magnetic stimulation using figure-8 and deep H-coils. J Clin Neurophysiol (2007) 24:31-8. doi:10.1097/ WNP.0b013e31802fa393

26. Spagnolo F, Volonte MA, Fichera M, Chieffo R, Houdayer E, Bianco M, et al. Excitatory deep repetitive transcranial magnetic stimulation with $\mathrm{H}$-coil as add-on treatment of motor symptoms in Parkinson's disease: an open label, pilot study. Brain Stimul (2014) 7:297-300. doi:10.1016/j.brs.2013.10.007

27. Hughes AJ, Daniel SE, Kilford L, Lees AJ. Accuracy of clinical diagnosis of idiopathic Parkinson's disease: a clinico-pathological study of 100 cases. $J$ Neurol Neurosurg Psychiatry (1992) 55:181-4. doi:10.1136/jnnp.55.3.181

28. Hoehn MM, Yahr MD. Parkinsonism: onset, progression and mortality. Neurology (1967) 17:427-42. doi:10.1212/WNL.17.5.427

29. Goetz CG, Tilley BC, Shaftman SR, Stebbins GT, Fahn S, Martinez-Martin P, et al. Movement disorder society-sponsored revision of the unified Parkinson's disease rating scale (MDS-UPDRS): scale presentation and clinimetric testing results. Mov Disord (2008) 23:2129-70. doi:10.1002/mds. 22340

30. Visser M, Marinus J, Stiggelbout AM, Van Hilten JJ. Assessment of autonomic dysfunction in Parkinson's disease: the SCOPA-AUT. Mov Disord (2004) 19:1306-12. doi:10.1002/mds.20153 
31. Martinez-Martin P, Benito-Leon J, Burguera JA, Castro A, Linazasoro G, Martinez-Castrillo JC, et al. The SCOPA-Motor Scale for assessment of Parkinson's disease is a consistent and valid measure. J Clin Epidemiol (2005) 58:674-9. doi:10.1016/j.jclinepi.2004.09.014

32. Mancini M, Priest KC, Nutt JG, Horak FB. Quantifying freezing of gait in Parkinson's disease during the instrumented timed up and go test. Conf Proc IEEE Eng Med Biol Soc (2012) 2012:1198-201. doi:10.1109/ EMBC.2012.6346151

33. Kegelmeyer DA, Kloos AD, Thomas KM, Kostyk SK. Reliability and validity of the Tinetti mobility test for individuals with Parkinson disease. Phys Ther (2007) 87:1369-78. doi:10.2522/ptj.20070007

34. Hamilton M. A rating scale for depression. J Neurol Neurosurg Psychiatry (1960) 23:56-62. doi:10.1136/jnnp.23.1.56

35. Beck AT, Ward CH, Mendelson M, Mock J, Erbaugh J. An inventory for measuring depression. Arch Gen Psychiatry (1961) 4:561-71. doi:10.1001/ archpsyc.1961.01710120031004

36. Wassermann EM. Side effects of repetitive transcranial magnetic stimulation. Depress Anxiety (2000) 12:124-9. doi:10.1002/1520-6394(2000)12:3<124::AID-DA3>3.0.CO;2-E

37. Levkovitz Y, Isserles M, Padberg F, Lisanby SH, Bystritsky A, Xia G, et al. Efficacy and safety of deep transcranial magnetic stimulation for major depression: a prospective multicenter randomized controlled trial. World Psychiatry (2015) 14:64-73. doi:10.1002/wps.20199

38. Cogiamanian F, Brunoni AR, Boggio PS, Fregni F, Ciocca M, Priori A. Non-invasive brain stimulation for the management of arterial hypertension. Med Hypotheses (2010) 74:332-6. doi:10.1016/j. mehy.2009.08.037

39. Udupa K, Sathyaprabha TN, Thirthalli J, Kishore KR, Raju TR, Gangadhar BN. Modulation of cardiac autonomic functions in patients with major depression treated with repetitive transcranial magnetic stimulation. J Affect Disord (2007) 104:231-6. doi:10.1016/j.jad.2007.04.002
40. Pal E, Nagy F, Aschermann Z, Balazs E, Kovacs N. The impact of left prefrontal repetitive transcranial magnetic stimulation on depression in Parkinson's disease: a randomized, double-blind, placebo-controlled study. Mov Disord (2010) 25:2311-7. doi:10.1002/mds.23270

41. Lidstone SC, Schulzer M, Dinelle K, Mak E, Sossi V, Ruth TJ, et al. Effects of expectation on placebo-induced dopamine release in Parkinson disease. Arch Gen Psychiatry (2010) 67:857-65. doi:10.1001/archgenpsychiatry.2010.88

42. Shetty N, Friedman JH, Kieburtz K, Marshall FJ, Oakes D. The placebo response in Parkinson's disease. Parkinson study group. Clin Neuropharmacol (1999) 22:207-12.

43. Goetz CG, Leurgans S, Raman R, Stebbins GT. Objective changes in motor function during placebo treatment in PD. Neurology (2000) 54:710-4 doi:10.1212/WNL.54.3.710

44. Fregni F, Boggio PS, Bermpohl F, Maia F, Rigonatti SP, Barbosa ER, et al. Immediate placebo effect in Parkinson's disease - is the subjective relief accompanied by objective improvement? Eur Neurol (2006) 56:222-9. doi:10.1159/000096490

Conflict of Interest Statement: FT, EV, and PP work at NeuroMagnetics SA. RR and JS are medical and scientific consultants for NeuroMagnetics SA and have financial interests in NeuroMagnetics SA, the representative of Brainsway Inc. in Chile. AZ serves as a research consultant and has financial interest in the Brainsway Inc. RM-A and SL have no conflicts of interest.

Copyright (C) 2015 Torres, Villalon, Poblete, Moraga-Amaro, Linsambarth, Riquelme, Zangen and Stehberg. This is an open-access article distributed under the terms of the Creative Commons Attribution License (CC BY). The use, distribution or reproduction in other forums is permitted, provided the original author(s) or licensor are credited and that the original publication in this journal is cited, in accordance with accepted academic practice. No use, distribution or reproduction is permitted which does not comply with these terms. 